\title{
Meloxicam increases intracellular accumulation of doxorubicin via downregulation of multidrug resistance-associated protein 1 (MRP1) in A549 cells
}

\author{
S.F. Chen, Z.Y. Zhang and J.L. Zhang \\ Department of Respiratory Medicine, The First Affiliated Hospital, \\ College of Medicine, Zhejiang University, Hangzhou, China \\ Corresponding author: S.F. Chen \\ E-mail: sfchen2015@163.com
}

Genet. Mol. Res. 14 (4): 14548-14560 (2015)

Received June 25, 2015

Accepted September 26, 2015

Published November 18, 2015

DOI http://dx.doi.org/10.4238/2015.November.18.18

\begin{abstract}
It has been suggested that selected COX inhibitors can overcome multidrug resistance through the inhibition of ATP-binding cassette-transporter proteins thereby enhancing the inhibitory effect of doxorubicin on human tumor growth and promoting the actions of cytostatics. However, their effect on lung cancer and the molecular mechanisms involved in the overcoming of multidrug resistance are unclear. In the present study, the ability of meloxicam, a COX-2-specific inhibitor to enhance doxorubicin-mediated inhibition was investigated in human A549 lung cancer in vivo and in vitro. In order to unravel the molecular mechanisms involved in doxorubicin accumulation, we measured the levels of multidrug resistance-associated protein (MRP)transporter protein activity and expression by western blotting, since this has been implicated in meloxicam action as well as in chemoresistance. We found that, in A549 cells, meloxicam could increase intracellular accumulation of doxorubicin, a substrate for MRP, through inhibition of cellular export. Western blot analysis indicated that meloxicam reduced
\end{abstract}


the expression of MRP1 and MRP4. The results reported in the present study demonstrate for the first time that the specific COX-2 inhibitor meloxicam can increase the intracellular accumulation of doxorubicin and enhance doxorubicin-induced cytotoxicity in A549 cancer cells by reducing the expression of MRP1 and MRP4.

Key words: Meloxicam; Doxorubicin; Lung cancer; MRP; Xenograft

\section{INTRODUCTION}

Non-steroidal anti-inflammatory drugs (NSAIDs) are widely prescribed analgesic and anti-inflammatory agents that exert biological effects through inhibition of the cyclooxygenase (COX) enzyme. The two isoforms of COX, COX-1 and COX-2, convert arachidonic acid to prostaglandin $\mathrm{G}$ and $\mathrm{H} 2$, which are subsequently converted to various eicosanoids having activities including anti-apoptosis, promotion of angiogenesis, and stimulation of estrogen synthesis (Lim et al., 2012). Preliminary studies identified upregulation of COX-2 expression in colorectal tumor tissue compared to that in non-tumor tissue. In addition, recent reports of experimental and clinical studies have shown promising effects of NSAIDs in the treatment of various cancers (Eberhart et al., 1994) including colorectal cancer (Cole et al., 2009), breast cancer (Zhao et al., 2009), esophageal and gastric cancer (Abnet et al., 2009), and lung cancer (Xu et al., 2012). An analysis of individual patient data from eight randomized trials showed that daily administration of aspirin could reduce the risk of death from cancer by approximately $20 \%$, compared to controls (Rothwell et al., 2011). Such a reduction in the incidence of cancer cannot be ignored.

Lung cancer is one of the most serious cancers worldwide with approximately 1.5 million newly diagnosed cases, and a death toll of an estimated 1 million people per year (Le Chevalier, 2010). There is increasing evidence that NSAIDs may have a protective role in lung cancer. Specifically, COX-2 was expressed at much higher levels in lung neoplastic tissue than that in non-tumor tissue (Wolff et al., 1998). Clinical evidence also suggested that COX-2 expression was associated with poor lung cancer survival in human subjects (Dannenberg et al., 2005). Experimental studies reported that NSAIDs and specific COX-2 inhibitors inhibited cell proliferation, cell motility, adhesion, angiogenesis, and the induction of apoptosis in tumors (Gately and Li, 2004). These anticancer properties suggest the potential for a treatment strategy that combines NSAIDs and COX-2 inhibitors with conventional anticancer therapies, such as chemotherapy (van Wijngaarden et al., 2007).

The mechanism by which NSAIDs and specific COX-2 inhibitors enhance the effect of cytostatic drugs is, however, not clear. There is a suggestion that the COX-inhibitors modulate the resistance of tumors to chemotherapeutic drugs by affecting the activity of plasma membrane transporter proteins of the ABC-transporter family, which behave as energydependent efflux pumps for cytostatics (van Wijngaarden et al., 2007). There are three key mammalian transporters involved in the transport of most anticancer agents: P-glycoprotein (P-gp/ABCB1), multidrug-resistance protein-1 (MRP1/ABCC1), and breast cancer resistance protein (BCRP/ABCC2) (Sparreboom et al., 2003).

In order to improve chemotherapeutic treatment, much effort has been invested to identify agents that are able to overcome multidrug resistance (MDR) by inhibiting P-gp, 
MRPs, or BCRP (de Jong et al., 2001) and COX inhibitors have been suggested as potential candidates (O'Connor et al., 2004). In the present study, we addressed these issues both in vivo and in vitro by studying the effects of NSAIDs and selective COX-2 inhibitors such as meloxicam, in combination with doxorubicin, on the A549 lung cancer cell line.

\section{MATERIAL AND METHODS}

\section{Cell lines, chemicals, and reagents}

The human lung cancer cell line A549 was purchased from the American Type Culture Collection (Rockville, MD, USA). RPMI 1640 cell culture medium (powder with L-glutamine and without sodium bicarbonate), phosphate-buffered saline (PBS, $0.01 \mathrm{M}$ ), pH 7.4, meloxicam, celecoxib, doxorubicin, probenecid, and phorbol 12-myristate 13-acetate (PMA) were purchased from Sigma-Aldrich (St. Louis, MO, USA). Drug-sensitive A549-EV cells and drug-resistant A549-MRP-OE cells, stably transfected with wild-type mrp, previously described by Chang et al. (1997), were routinely grown at $37^{\circ} \mathrm{C}$ in RPMI 1640 supplemented with $10 \%$ fetal bovine serum, $100 \mathrm{IU} / \mathrm{mL}$ penicillin, and $100 \mathrm{mg} / \mathrm{mL}$ streptomycin in a $5 \%$ $\mathrm{CO}_{2} / 95 \%$ air humidified atmosphere according to standard protocols (Maeng et al., 2014).

\section{Animal study}

Female BALB/c nu/nu mice were obtained from the Experimental Animal Center of the Zhejiang Academy of Medical Sciences and were housed in individual ventilated cages under sterile conditions according to the Swiss guidelines for the care and use of laboratory animals. Sterile food and water were provided ad libitum. The experimental procedures were approved by the Institutional Animal Care and Use Committee of Zhejiang University. Mice were maintained on a regular light-dark cycle (lights on at 10:00 am, lights off at 10:00 pm; room temperature $20^{\circ}-22^{\circ} \mathrm{C}$; room relative humidity $65 \%$; and a maximum of 3 animals per cage). Mice, approximately 10 weeks old were injected in the left flank with A549 cells ( $2 \mathrm{x}$ $10^{6}$ cells $\left./ 100 \mu \mathrm{L}\right)$ or A549 cells overexpressing MRP1 $\left(2 \times 10^{6}\right.$ cells $\left./ 100 \mu \mathrm{L}\right)$. After 10 days, animals having a tumor with a volume (TV) of $20 \pm 3 \mathrm{~mm}^{3}$ were selected and randomly divided into four groups of eight mice each. TV was assessed by using a caliper to measure the axes and calculated by the formula $\mathrm{TV}=\pi / 6(\mathrm{~d} 1 \mathrm{x} \mathrm{d} 2)^{1 / 2}$ (Van Wijngaarden et al., 2007). Mice (8 per experimental group) were injected intraperitoneally with control (DMSO), meloxicam $(15 \mathrm{mg} / \mathrm{kg})$, doxorubicin $(0.5 \mathrm{mg} / \mathrm{kg})$, or a combination of meloxicam and doxorubicin in a total volume of $100 \mu \mathrm{L}$ according to previous results (data not shown). The mice were treated every other day for 30 days. TV and body weight were measured every 4 days. After 30 days, all the mice were sacrificed and samples collected.

\section{Terminal deoxynucleotidyl transferase-mediated deoxyuridine triphosphate nick end-labeling (TUNEL) assay}

Apoptosis mediated by doxorubicin, meloxicam, or a combination of the two was detected by the enzymatic labeling of DNA strand breaks, using TUNEL stain in a Cell Death Detection kit (Roche, Mannheim, Germany) according to the manufacturer instructions. The apoptotic ratio was measured by flow cytometry, according to the manufacturer instructions. 


\section{Drug-sensitivity assay}

The effects of drugs on cell proliferation were evaluated using the $(3-(4,5-$ dimethylthiazol-2-yl)-2,5-diphenyltetrazolium bromide (MTT) assay (Cell Titer 96 Aqueous, Promega) for 4 groups (control, DMSO; doxorubicin, 0.01-0.5 $\mu \mathrm{M}$; doxorubicin and meloxicam combination; doxorubicin and celecoxib combination). Celecoxib was used as the positive control. Briefly, $1.5 \times 10^{5}$ cells per well were seeded in triplicate in 90 $\mu \mathrm{L}$ culture medium on 96-well flat-bottom microculture plates and pre-cultured for 1 day before the addition of the test drugs. After 4 days of culture, the number of viable cells was determined by adding $100 \mu \mathrm{L} 1 \mathrm{mg} / \mathrm{mL}$ MTT solution to each well and measuring optical density (OD) at $540 \mathrm{~nm}$ (Thermomax, Molecular Devices) after a 2-h incubation. The results are reported as the mean OD of each 3-well set. Growth inhibition was evaluated as $\mathrm{IC}_{50}$, the drug concentration resulting in a 50\% reduction in cell number, as compared to controls cultured in parallel without the drug.

\section{Doxorubicin accumulation assay}

The doxorubicin accumulation in the A549 cell assay was as described by van Wijngaarden et al. (2007), with slight modifications. Briefly, A549 cells were incubated for $24 \mathrm{~h}$ in medium containing doxorubicin $(0.5,1$, or $5 \mu \mathrm{M})$, with or without meloxicam (50 $\mu \mathrm{M})$, or celecoxib $(50 \mu \mathrm{M})$. Cells $\left(1.5 \times 10^{5}\right)$ were seeded on 4-well Lab-Tek glass Chamber Slides (Nalge Nunc International Corp., Naperville, IL, USA) and incubated overnight, after which test materials were added and incubated for $24 \mathrm{~h}$. Subsequently, the culture medium was removed and cells were washed thrice with PBS. Cells were fixed in $4 \%$ paraformaldehyde for $10 \mathrm{~min}$ at room temperature, washed thrice with PBS and mounted under glass coverslips with Vectashield mounting medium (Brunschwig, Amsterdam, Netherlands). The cells were examined for doxorubicin fluorescence using fluorescence microscopy with excitation at $465-495 \mathrm{~nm}$ and detection at an emission maximum of 515$555 \mathrm{~nm}$. Intracellular doxorubicin was quantified using computerized image analysis. Cells were measured and values are reported as mean light intensity per cell $\pm \mathrm{SD}$, corrected for background.

\section{MRP activity analysis}

Calcein is an anionic fluorescent probe substrate for MRP, which can be used to assay the enzyme activity (Feller et al., 1995). For calcein accumulation experiments, cells were incubated in RPMI medium for $1 \mathrm{~h}$ with calcein acetomethoxy $(0.5 \mu \mathrm{M})$ and various concentration of meloxicam $(0,25,50,100,200 \mu \mathrm{M})$ and probenecid (MRPspecific inhibitor, $200 \mu \mathrm{M}$ ). Drug-sensitive A549-EV cells and drug-resistant A549-MRPOE cells were then washed thrice with ice-cold PBS and lysed by ultrasonication in distilled water. The amount of intracellular calcein was determined by fluorometry using a Titertek Fluoroscan spectrofluorometer (Flow Laboratories, Puteaux, France) at excitation and emission wavelengths of 485 and $538 \mathrm{~nm}$, respectively. Results are reported as fluorescence arbitrary units after normalization to the amount of cellular protein measured by the BioRad assay in an aliquot of cell lysate. 


\section{Western blot analysis}

Six treatment groups: control, DMSO; COX-2 inducer: PMA (10 nM); meloxicam $(50 \mu \mathrm{M})$; celecoxib $(50 \mu \mathrm{M})$; PMA $(10 \mathrm{nM})$ with meloxicam $(50 \mu \mathrm{M})$; and PMA $(10 \mathrm{nM})$ with celecoxib $(50 \mu \mathrm{M})$ were prepared for western blot analysis. Cytoplasmic or nuclear protein $(40 \mu \mathrm{g})$ was prepared from cells treated for $24 \mathrm{~h}$ under different conditions and separated on a $10 \%$ SDS-polyacrylamide gel overlaid with a $4 \%$ polyacrylamide-stacking gel. After separation, proteins were electroblotted onto a nitrocellulose membrane (Amersham Biosciences, Piscataway, NJ, USA). The membrane was blocked with $5 \%$ nonfat dry milk in Tris-buffered saline containing $0.1 \%$ Tween 20 (TBS-T, $\mathrm{pH}$ 7.4) for $1 \mathrm{~h}$ at room temperature and then membrane was washed with $0.1 \%$ TBS-T and incubated with primary antibodies against MRP1 (sc-365635, Santa Cruz), MRP2 (sc-59609, Santa Cruz), MRP3 (sc-5776, Santa Cruz), MRP4 (sc-59614, Santa Cruz), MRP5 (sc-376965, Santa Cruz), and $\beta$-actin (sc47778 , Santa Cruz) in $0.1 \%$ TBS-T overnight at $4^{\circ} \mathrm{C}$. The membrane was then washed thrice with $0.1 \%$ TBS-T and incubated with the secondary antibody (1:5000 dilutions of anti-rat for MRP1, MRP2, MRP3, MRP4, MRP5; and anti-mouse for $\beta$-actin) for $1 \mathrm{~h}$ at room temperature, followed by three washings with $0.1 \%$ TBS-T.

\section{Statistical analysis}

Data are reported as means $\pm \mathrm{SD}$ and the Student $t$-test was used for comparing treated groups with controls. A P value of $<0.05$ was considered to be significant. All statistical analyses were performed using Prism 5 (GraphPad Software, La Jolla, CA, USA).

\section{RESULTS}

\section{A549 tumor growth inhibition in vivo}

All the mice survived the experiments, apart from one animal in the control group and one in the meloxicam group. Results of the subcutaneous growth of A549 human lung cancer cell xenotrans plantated in nude mice are shown in Figure 1. After 30 days of treatment, there was significant suppression $(\mathrm{P}<0.05)$ of the average tumor volume in mice treated with a combination of doxorubicin $(0.5 \mathrm{mg} / \mathrm{kg})$ and meloxicam $(15 \mathrm{mg} / \mathrm{kg})$ compared to the control group. However, treatment with either doxorubicin or meloxicam as single agents did not significantly affect tumor growth under these conditions. This suggested that the inhibitory effect of doxorubicin on A549 growth in vivo was enhanced by a combination with meloxicam.

\section{Effect of meloxicam on doxorubicin-induced A549 tumor apoptosis}

To our knowledge, there have not been any previous studies that investigated the role of meloxicam during doxorubicin-induced apoptosis in A549 tumor. We used TUNEL staining with flow cytometry to observe the effects of meloxicam $(15 \mathrm{mg} / \mathrm{kg})$, doxorubicin $(0.5 \mathrm{mg} / \mathrm{kg})$, or a combination of the two drugs and showed that meloxicam increased apoptotic cell death in the A549 tumor, compared to a single administration of doxorubicin (Figure 2). 


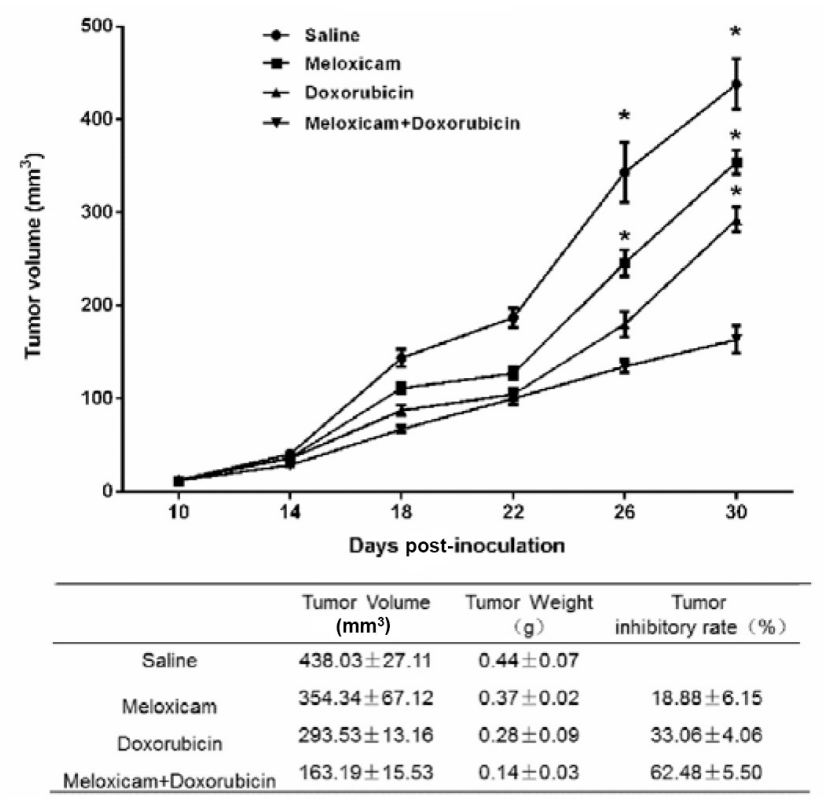

Figure 1. Meloxicam $(15 \mathrm{mg} / \mathrm{kg})$ and doxorubicin $(0.5 \mathrm{mg} / \mathrm{kg})$ alone or in combination induce A549 tumor regression in vivo. Mice with A549 tumor xenografts were treated with saline (control) or with different drugs, either alone or in combination followed by measurement of tumor size every 4 days for a total of 30 days. Percent change in tumor size was calculated relative to the size of the tumor before treatment. The tumor volume, tumor weight, and tumor-inhibitory rate was averaged from data obtained from 8 mice per group. ${ }^{*} \mathrm{P}<0.05$ compared to saline-treated controls.

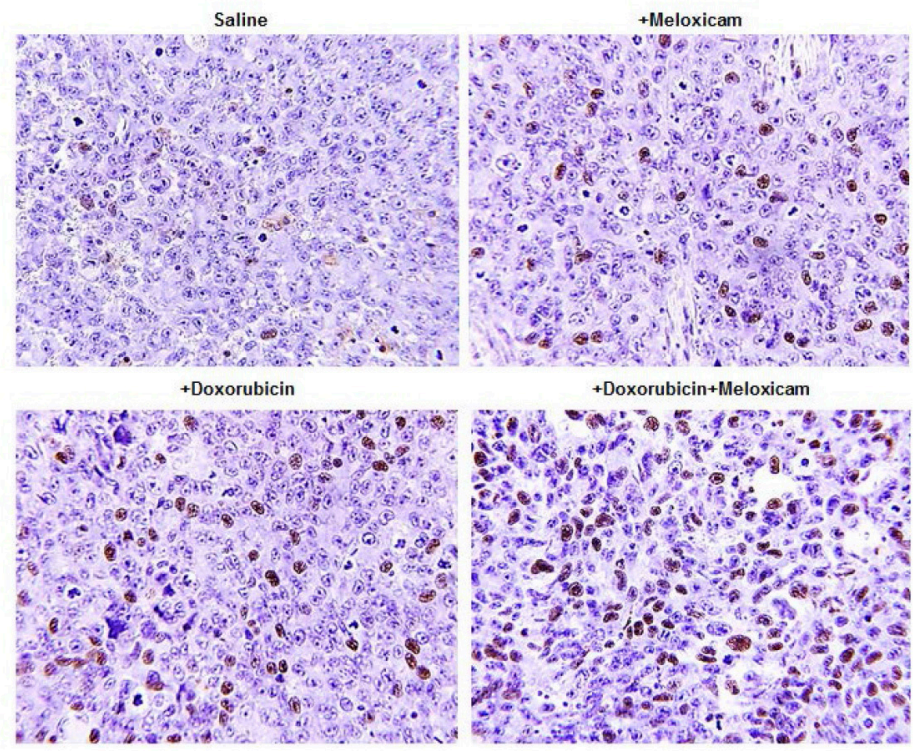

Figure 2. Effect of meloxicam on doxorubicin-induced A549 tumors. Results of TUNEL staining to assess changes in apoptosis with doxorubicin treatment alone and in combination with meloxicam in the A549 tumor xenograft model. 


\section{Doxorubicin sensitivity against A549 in vitro}

The effect of doxorubicin on A549 cells in the presence or absence of meloxicam (10 $\mu \mathrm{M})$ and celecoxib $(10 \mu \mathrm{M})$ is shown in Table 1. Doxorubicin inhibited cell proliferation in a dose-dependent fashion with an $\mathrm{IC}_{50}$ of $0.61 \pm 0.14 \mu \mathrm{M}$. Although meloxicam or celecoxib, alone had no effect on cell growth, when they were used in combination with doxorubicin, the $\mathrm{IC}_{50}$ decreased to $0.34 \pm 0.08 \mu \mathrm{M}$ (meloxicam) and $0.44 \pm 0.11 \mu \mathrm{M}$ (celecoxib). These results demonstrated that a combination of drugs decreased the $\mathrm{IC}_{50}$ value of doxorubicin against A549 cells in vitro.

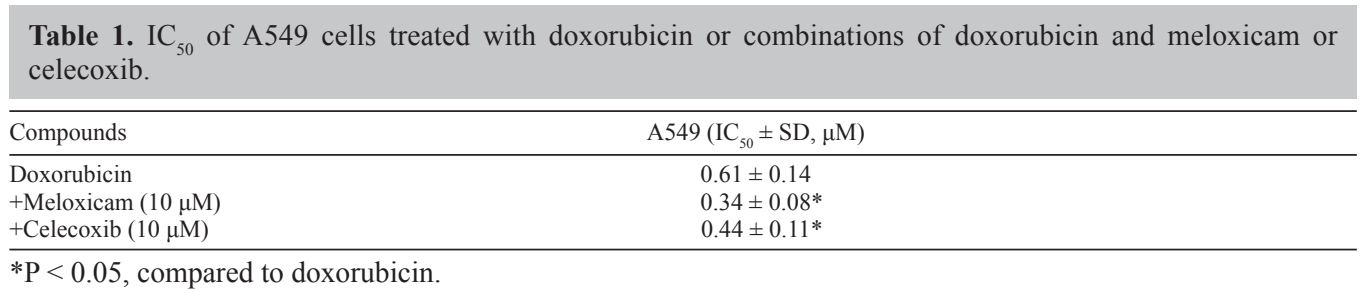

\section{Intracellular accumulation of doxorubicin}

Doxorubicin is an auto-fluorescent compound, which enables intracellular visualization by fluorescence microscopy. Figure 3 shows the fluorescence of intracellularaccumulated doxorubicin in A549 cells after a 24-h incubation with different concentrations of doxorubicin $(0.5,1$, and $5 \mu \mathrm{M})$ in the absence $(\mathrm{A}, \mathrm{D}$, and $\mathrm{G})$ or presence of meloxicam $(50 \mu \mathrm{M}, \mathrm{B}, \mathrm{E}$, and $\mathrm{H})$ or celecoxib $(50 \mu \mathrm{M}, \mathrm{C}, \mathrm{F}$, and I). The figure demonstrates that at all concentrations, the intracellular fluorescence was significantly $(5 \mu \mathrm{M}, \mathrm{P}<0.05 ; 0.5$ and $1 \mu \mathrm{M}$, $\mathrm{P}<0.01)$ higher in cells that were co-treated with meloxicam or celecoxib and doxorubicin, compared to doxorubicin alone.

\section{MRP activity measured by analysis of calcein accumulation}

Doxorubicin is a substrate for proteins of the MRP-transporter protein family known to enhance the efflux of cytostatic drugs. Since the present hypothesis suggests that meloxicam modulates the cellular actions of doxorubicin via inhibition of MRP transporters, we examined the MRP activity by analyzing the accumulation of calcein. The effects of various concentrations of meloxicam on the accumulation of the MRP substrate calcein were determined in drug-sensitive A549-EV cells and drug-resistant A549-MRPOE cells. Figure 4 shows that meloxicam increased calcein levels in A549-MRP-OE cells in a dose-dependent manner. A concentration of $50 \mu \mathrm{M}$ meloxicam enhanced the cellular dye-related fluorescence by approximately $30 \%$, and higher concentrations of 100 and 200 $\mu \mathrm{M}$, increased the levels of calcein by approximately 70 and $120 \%$, respectively, although $25 \mu \mathrm{M}$ meloxicam was ineffective. In addition, meloxicam had no effect on MRP activity in A549-EV cells. 

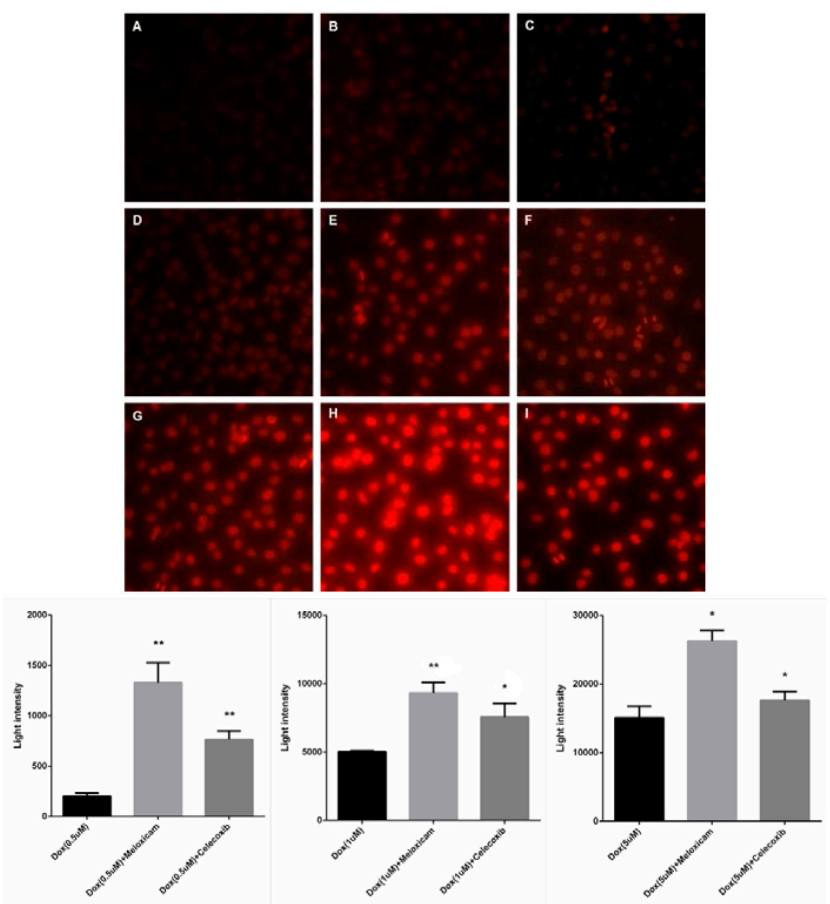

Figure 3. Effect of meloxicam and celecoxib (positive control) on the intracellular accumulation of doxorubicin. A-I show fluorescent microscopic pictures of A549 cells that were incubated for $24 \mathrm{~h}$ in a medium containing doxorubicin $0.5 \mu \mathrm{M}(\mathbf{A}), 1 \mu \mathrm{M}(\mathbf{D})$, or $5 \mu \mathrm{M}(\mathbf{G})$, or these concentrations of doxorubicin in combination with meloxicam $50 \mu \mathrm{M}(\mathbf{B}, \mathbf{E}, \mathbf{H})$ and celecoxib $50 \mu \mathrm{M}(\mathbf{C}, \mathbf{F}, \mathbf{I})$, respectively. Magnification: 200X. For all experimental conditions, the bar graphs show the mean light intensity per cell, measured by computerized image analysis, and reported as means $\pm \mathrm{SD}, * \mathrm{P}<0.05, * * \mathrm{P}<0.01$.

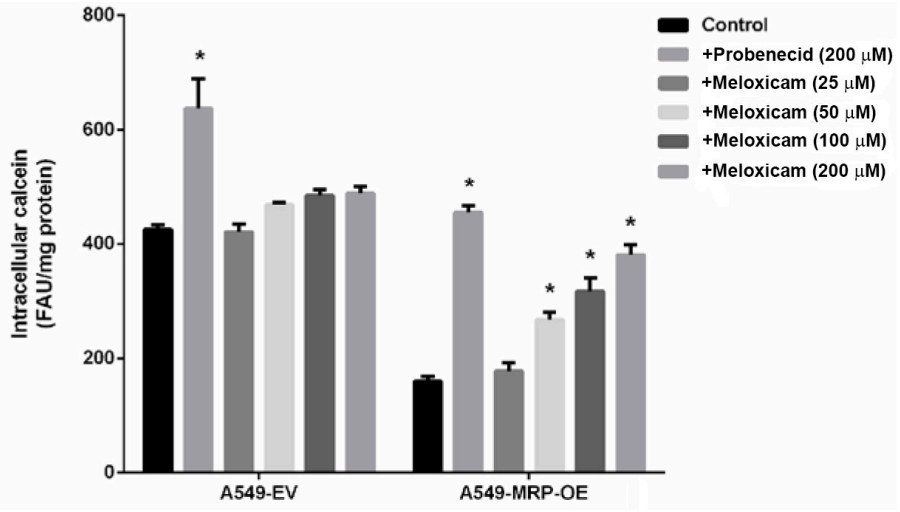

Figure 4. Effect of various concentrations of meloxicam on calcein accumulation in drug-sensitive A549-EV cells and drug-resistant A549-MRP-OE cells. Cells were incubated with $0.5 \mu \mathrm{M}$ calcein in the presence of various doses of meloxicam (from 0 to $200 \mu \mathrm{M}$ ). Probenecid, a specific MRP inhibitor, was used as the positive control. Intracellular calcein accumulation was determined by fluorimetry. The values are reported as fluorescence arbitrary units (FAU) normalized to protein content and are means $\pm \mathrm{SD}$ of three independent experiments in triplicate. $* \mathrm{P}$ $<0.05$ compared to control. 


\section{Downregulation of COX-2 suppressed the levels of MRP1 and MRP4 in A549 cells}

To further demonstrate the relationship between meloxicam and MRP activity, cells were treated with PMA in the presence of meloxicam, and the levels of MRP1, MRP2, MRP3, MRP4, and MRP5 proteins were investigated using western blot analysis. As shown in Figure 5, meloxicam significantly suppressed the PMA-induced levels of MRP1 and MRP4. In contrast, the levels of MRP2, MRP3, and MRP5 remained unaffected. These results demonstrate that the specific COX-2 inhibitor, meloxicam, can increase doxorubicin cytotoxicity against A549 cells through downregulation of MRP1 and MRP4, which decreases the efflux of the drug.

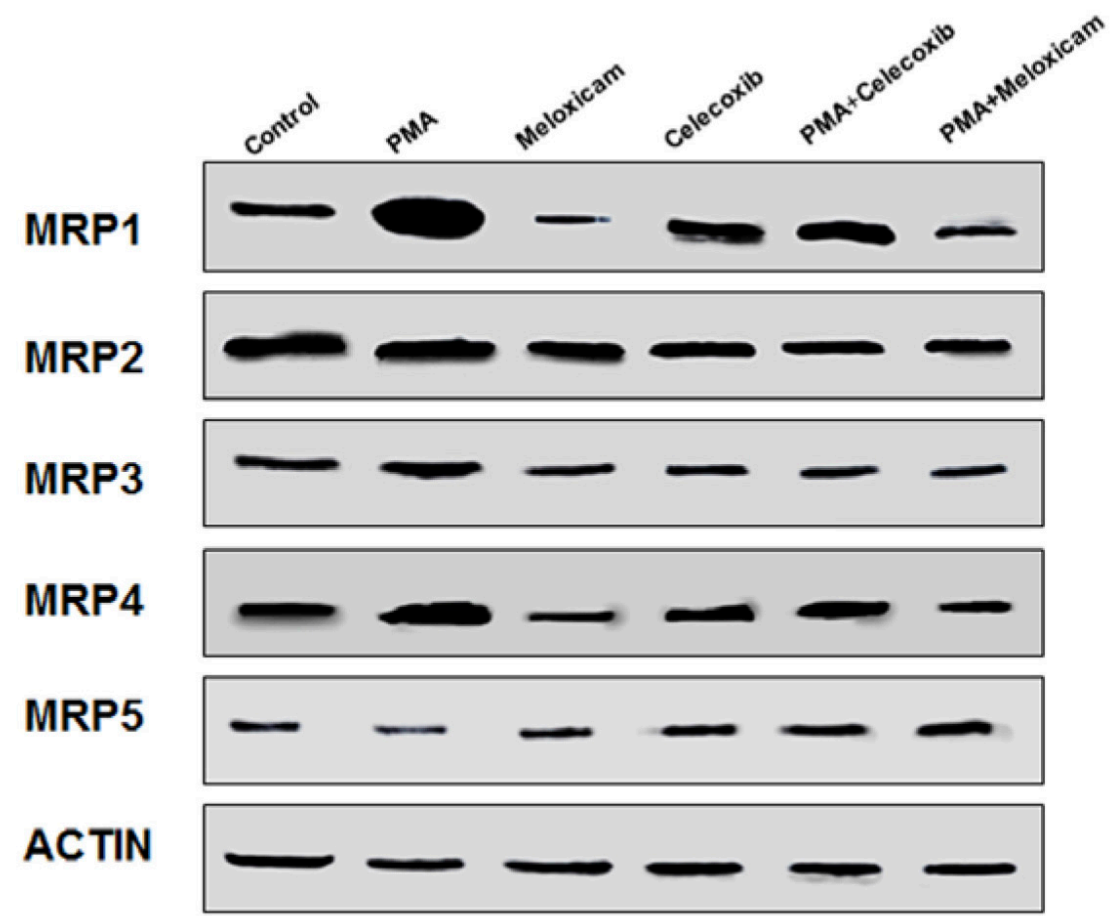

Figure 5. Western blot detection of MRP1, MRP2, MRP3, MRP4, and MRP5 protein levels from drug-resistant A549-MRP-OE cells. A549-MRP-OE cells were cultured for $24 \mathrm{~h}$ in the absence (control) or presence of PMA (COX-2 inducing, $10 \mathrm{nM})$, meloxicam $(50 \mu \mathrm{M})$, celecoxib $(50 \mu \mathrm{M})$, PMA $(10 \mathrm{nM})$ in combination with celecoxib $(50 \mu \mathrm{M})$, and PMA $(10 \mathrm{nM})$ in combination with meloxicam $(50 \mu \mathrm{M})$.

\section{DISCUSSION}

Meloxicam, a derivative of enolic acid, is a widely used NSAID with anti-inflammatory, antipyretic, and analgesic properties, and exerts its effects through the inhibition of COX, specifically the COX-2 enzyme (Furst, 1997). There have been a number of reports that meloxicam has anti-tumor properties in different cancer cell lines, including prostate (Montejo et al., 2010), colorectal (Goldman et al., 1998), and non-small lung cancer cells (Tsubouchi et al., 2000). In this study, we showed that meloxicam also significantly increased the intracellular accumulation and retention of doxorubicin in vitro. These effects of meloxicam 
were dependent on COX inhibition and of downregulation of MRP activity.

COX-2 is the only isoform that has been associated with carcinogenesis (Williams et al., 1999), given that it is expressed in several malignant tumors (Gupta et al., 2000). The therapeutic effects of selective COX-2 inhibitors have already been assessed in vivo (human hepatocellular carcinoma implants in nude mice) and in vitro (canine osteosarcoma) models with encouraging outcomes (Wolfesberger et al., 2006). Previous studies have shown that NSAIDs and specific COX-2 inhibitors are able to enhance the effects of certain cytostatic agents both in vitro and in vivo. For example, celecoxib was shown to enhance the ability of doxorubicin to inhibit tumor growth in breast tumor-bearing mice (Awara et al., 2004) and in human breast carcinoma MDA-MB231 xenografts in nude mice (van Wijngaarden et al., 2007). In one casecontrol study that focused on selective COX-2 blockade and lung cancer risk, there was a significant reduction in the risk of lung cancer following daily administration of drugs such as celecoxib or rofecoxib over 2 years or more (Harris et al., 2007). The combination of either aspirin or celecoxib with 5-fluorouracil (5-FU) was capable of improving chemosensitivity in chemorefractory colorectal cancer cells in vitro, but a synergistic effect with 5-FU could only be demonstrated with celecoxib (Rahman et al., 2012). Treatment of bladder cancer cells with a combination of sunitinib malate and meloxicam showed a synergistic effect, and there was an increase in the number of autophagic vacuoles and early apoptotic cells when the combined treatment was employed (Arantes-Rodrigues et al., 2013). In accordance with these results, we showed here that the treatment of human lung cancer A549 xenografts in nude mice with a combination of doxorubicin and meloxicam inhibited tumor growth both in vitro and in vivo more efficiently than doxorubicin treatment alone (Figure 1 and Table 1).

MDR is a major cause of cancer treatment failure when using cytostatic drugs (Mansilla et al., 2007) and the mechanism by which tumor cells acquire this drug resistance is probably through overexpression of membrane transport proteins that effectively efflux them (Garnier-Suillerot et al., 2001). The best-characterized mechanism of MDR is mediated through the overexpression of $\mathrm{ABC}$ transporter superfamily members, for example P-gp (MDR-1) and the multidrug resistant-associated protein (MRP-1) (Deeley and Cole, 2006). MRP-1, originally isolated from a doxorubicin-selected lung cancer cell line, mediates resistance to a broad range of anticancer drugs (Gottesman et al., 2002). As the increased expression of either the MRP-1 gene or the MDR-1 gene in various cancers including small cell lung cancer, the combination of anti-cancer agents together with MRP inhibitors to limit the drug efflux, is an obvious direction for developments in chemotherapy (Canitrot et al., 1998).

MDR-1 activity can be inhibited by a wide variety of drugs including calcium channel blockers such as verapamil, immunosuppressive agents such as cyclosporin A, as well as phenothiazines and steroids (Ford and Hait, 1990). These compounds, termed modulators or chemosensitizers, enhance the intracellular retention of anticancer drugs in MDR-1overexpressing cells and thus circumvent drug resistance (Sikic, 1993). Unfortunately, in contrast to MDR-1-mediated resistance, MRP is affected by only a few agents (Garnier-Suillerot et al., 2001). However, the MDR-1 inhibitors, verapamil and cyclosporin A, have also been found to increase the accumulation of the MRP substrate, daunorubicin in drug-resistant cells (Lautier et al., 1996). Another report indicated that rifamycins, including rifampicin, might constitute a new class of chemical modulators, which downregulate MRP-mediated drug transport (Courtois et al., 1999).

Previous studies using less specific or sensitive assays suggested that the enhancement 
of cytostatic drug efficacy by COX inhibitors, such as celecoxib, might be due to inhibition of MDR-1 (Awara et al., 2004) or MRP-1 (O'Connor et al., 2004). In our study, we show that both meloxicam and celecoxib augmented the in vitro intracellular accumulation and retention of doxorubicin, also suggesting the possible involvement of one of the doxorubicin transporters (Figure 3). Recently, the combination of NSAIDs with anticancer drugs gained attention as a treatment option because NSAIDs can inhibit the COX-2/PGE 2 pathway in cancer cells (Maeng et al., 2014). An additional study indicated that NSAIDs also inhibit the overexpression of MRP4 in lung cancer, which is most likely to be advantageous and result in enhanced accumulation of anticancer agents that would otherwise be ejected from the cell. However, there may be additional mechanisms that regulate MRP4 expression, since treatment with the COX-2-specific inhibitor celecoxib was ironically reported to increase the expression of MRP4 in the lung (Gradilone et al., 2007) and colon cancer (Gradilone et al., 2008).

A previous study showed that the specific COX-2-specific inhibitor celecoxib enhanced the inhibitory effect of doxorubicin on human MDA-MB231 breast tumor growth in vivo and in vitro and increased the intracellular accumulation and retention of doxorubicin in vitro (Feller et al., 1995). However, the study concluded that structurally different compounds, including celecoxib and PSC833, the MDR-1 blocker, acted most likely through the modulation of NF- $\mathrm{kB}$ activity (O'Connor et al., 2004). Upregulation of COX-2 in A549 cells could promote the overexpression of multidrug resistance protein 4 (MRP4) via a $\mathrm{PGE}_{2}$-dependent pathway (Goldman et al., 1998). In the present study, we demonstrated by western blotting that meloxicam inhibited the PMA-stimulated expression of MRP1 and MRP4 in A549 cells. It seems reasonable that meloxicam may also downregulate the MRP1 and MRP4 overexpression because of the presence of COX in these cells. The results shown in Figure 4, indicate that meloxicam increased calcein cell accumulation in normal A549 cells, but not in A549-MRP-OE cells. Further studies should be designed to determine the mechanism of COX-moderated meloxicam inhibition of the expression of MRP1 and MRP4 in cancer cells.

In conclusion, our results showed that meloxicam increased the intracellular accumulation of calcein, a fluorescent dye substrate for MRP, in A549 cells through inhibition of extracellular export. Moreover, meloxicam also enhanced the accumulation of the anticancer drug, doxorubicin, another known substrate of MRP in A549 cells. The results from the western blot analysis reported in the present study indicate for the first time that meloxicam reduces the expression of MRP1 and MRP4.

\section{Conflicts of interest}

The authors declare no conflict of interest.

\section{ACKNOWLEDGMENTS}

Experimental animals were provided by the Experimental Animal Center of the Zhejiang Academy of Medical Sciences. The design of the experiments was supported by Prof. Jianying Zhou. Research supported by the Science and Technology Development Fund Projects of the First Affiliated Hospital, College of Medicine, Zhejiang University (Grant \#B1519). 


\section{REFERENCES}

Abnet CC, Freedman ND, Kamangar F, Leitzmann MF, et al. (2009). Non-steroidal anti-inflammatory drugs and risk of gastric and oesophageal adenocarcinomas: results from a cohort study and a meta-analysis. Br. J. Cancer 100: 551-557.

Arantes-Rodrigues R, Pinto-Leite R, Fidalgo-Goncalves L, Gaivao I, et al. (2013). Meloxicam synergistically enhances the in vitro effects of sunitinib malate on bladder-cancer cells. J. Appl. Biomed. 11: 79-92.

Awara WM, El-Sisi AE, El-Sayad ME and Goda AE (2004). The potential role of cyclooxygenase-2 inhibitors in the treatment of experimentally-induced mammary tumour: does celecoxib enhance the anti-tumour activity of doxorubicin? Pharmacol. Res. 50: 487-498.

Canitrot Y, Bichat F, Cole SP, Deeley RG, et al. (1998). Multidrug resistance genes (MRP) and MDR1 expression in small cell lung cancer xenografts: relationship with response to chemotherapy. Cancer Lett. 130: 133-141.

Chang XB, Hou YX and Riordan JR (1997). ATPase activity of purified multidrug resistance-associated protein. J. Biol. Chem. 272: 30962-30968.

Cole BF, Logan RF, Halabi S, Benamouzig R, et al. (2009). Aspirin for the chemoprevention of colorectal adenomas: metaanalysis of the randomized trials. J. Natl. Cancer Inst. 101: 256-266.

Courtois A, Payen L, Vernhet L, de Vries EG, et al. (1999). Inhibition of multidrug resistance-associated protein (MRP) activity by rifampicin in human multidrug-resistant lung tumor cells. Cancer Lett. 139: 97-104.

Dannenberg AJ, Lippman SM, Mann JR, Subbaramaiah K, et al. (2005). Cyclooxygenase-2 and epidermal growth factor receptor: pharmacologic targets for chemoprevention. J. Clin. Oncol. 23: 254-266.

de Jong MC, Slootstra, JW, Scheffer GL, Schroeijers AB, et al. (2001). Peptide transport by the multidrug resistance protein MRP1. Cancer Res. 61: 2552-2557.

Deeley RG and Cole SP (2006). Substrate recognition and transport by multidrug resistance protein 1 (ABCC1). FEBS Lett. 580: 1103-1111.

Eberhart CE, Coffey RJ, Radhika A, Giardiello FM, et al. (1994). Up-regulation of cyclooxygenase 2 gene expression in human colorectal adenomas and adenocarcinomas. Gastroenterology 107: 1183-1188.

Feller N, Broxterman HJ, Wahrer DC and Pinedo HM (1995). ATP-dependent efflux of calcein by the multidrug resistance protein (MRP): no inhibition by intracellular glutathione depletion. FEBS Lett. 368: 385-388.

Ford JM and Hait WN (1990). Pharmacology of drugs that alter multidrug resistance in cancer. Pharmacol. Rev. 42: 155-199.

Furst DE (1997). Meloxicam selective COX-2 inhibition in clinical practice. Semin. Arthritis Rheum. 26: 21-27.

Garnier-Suillerot A, Marbeuf-Gueye C, Salerno M, Loetchutinat C, et al. (2001). Analysis of drug transport kinetics in multidrug-resistant cells: implications for drug action. Curr. Med. Chem. 8: 51-64.

Gately S and Li WW (2004). Multiple roles of COX-2 in tumor angiogenesis: a target for antiangiogenic therapy. Semin. Oncol. 31: 2-11.

Goldman AP, Williams CS, Sheng H, Lamps LW, et al. (1998). Meloxicam inhibits the growth of colorectal cancer cell. Carcinogenesis 19: 2195-2199.

Gottesman MM, Fojo T and Bates SE (2002). Multidrug resistance in cancer: role of ATP-dependent transporters. Nat. Rev. Cancer 2: 48-58.

Gradilone A, Pulcinelli FM, Lotti LV, Martino S, et al. (2007). Celecoxib induces MRP-4 in lung cancer cells: therapeutic implications. J. Clin. Oncol. 25: 4318-4320.

Gradilone A, Pulcinelli FM, Lotti LV, Trifiro E, et al. (2008). Celecoxib upregulates multidrug resistance proteins in colon cancer: lack of synergy with standard chemotherapy. Curr. Cancer Drug Targets 8: 414-420.

Gupta S, Srivastava M, Ahmad N, Bostwick DG, et al. (2000). Over-expression of cyclooxygenase-2 in human prostate adenocarcinoma. Prostate 42: 73-78.

Harris L, Fritsche H, Mennel R, Norton L, et al. (2007). American Society of Clinical Oncology 2007 update of recommendations for the use of tumor markers in breast cancer. J. Clin. Oncol. 25: 5287-5312.

Lautier D, Canitrot Y, Deeley RG and Cole SPC (1996). Multidrug resistance mediated by the multidrug resistance protein (MRP) gene. Biochem. Pharmacol. 52: 967-977.

Le Chevalier T (2010). Adjuvant chemotherapy for resectable non-small-cell lung cancer: where is it going? Ann. Oncol. 21: 196-198.

Lim WY, Chuah KL, Eng P, Leong SS, et al. (2012). The aspirin and non-aspirin non-steroidal anti-inflammatory drug use and risk of lung cancer. Lung Cancer 77: 246-251.

Maeng HJ, Lee WJ, Jin QR, Chang J, et al. (2014). Upregulation of COX-2 in the lung cancer promotes overexpression of multidrug resistance protein 4 (MRP4) via PGE $_{2}$-dependent pathway. Eur. J. Pharm. Sci. 62: 189-196.

Mansilla S, Rojas M, Bataller M, Priebe W, et al. (2007). Circumvention of the multidrug-resistance protein (MRP-1) by an antitumor drug through specific inhibition of gene transcription in breast tumor cells. Biochem. Pharmacol. 73: 934-942. 
Montejo C, Barcia E, Negro S and Fernandez-Carballido A (2010). Effective antiproliferative effect of meloxicam on prostate cancer cells: Development of a new controlled released system. Int. J. Pharm. 387: 223-229.

O’Connor R, Heenan M, Connolly L, Larkin A, et al. (2004). Increased anti-tumor efficacy of doxorubicin when combined with sulindac in a xenograft model of an MRP-1 positive human lung cancer. Anticancer Res. 24: 457-464.

Rahman M, Selvarajan K, Hasan MH, Chan AP, et al. (2012). Inhibition of COX-2 in colon cancer modulates tumor growth and MDR-1 expression to enhance tumor regression in therapy-refractory cancers in vivo. Neoplasia 14: 624-633.

Rothwell PM, Fowkes FG, Belch JF, Ogawa H, et al. (2011). Effect of daily aspirin on long-term risk of death due to cancer: analysis of individual patient data from randomized trials. Lancet 377: 31-41.

Sikic BI (1993). Modulation of multidrug resistance: at the threshold. J. Clin. Oncol. 11: 1629-1635.

Sparreboom A, Danesi R, Ando Y, Chan J, et al. (2003). Pharmacogenomics of ABC transporters and its role in cancer chemotherapy. Drug Resist. Update 6: 71-84.

Tsubouchi Y, Mukai S, Kawahito Y, Yamada R, et al. (2000). Meloxicam inhibits the growth of non-small cell lung cancer. Anticancer Res. 20: 2867-2872.

Van Wijngaarden J, van Beek E, van Rossum G, van der Bent C, et al. (2007). Celecoxib enhances doxorubicin-induced cytotoxicity in MDA-MB231 cells by NF-kappaB-mediated increase of intracellular doxorubicin accumulation. Eur. J. Cancer 43: 433-442.

Williams CS, Mann M and DuBois RN (1999). The role of cyclooxygenases in inflammation, cancer, and development. Oncogene 18: 7908-7916.

Wolfesberger B, Hoelzl C, Walter I, Reider GA, et al. (2006). In vitro effects of meloxicam with or without doxorubicin on canine osteosarcoma cells. J. Vet. Pharmacol. Ther. 29: 15-23.

Wolff H, Saukkonen K, Antilla S, Karjalainen A, et al. (1998). Expression of cyclooxygenase-2 in human lung carcinoma. Cancer Res. 58: 4997-5001.

Xu J, Yin Z, Gao W, Liu L, et al. (2012). Meta-analysis on the association between non-steroidal anti-inflammatory drug use and lung cancer risk. Clin. Lung Cancer 13: 44-51.

Zhao YS, Zhu S, Li XW, Wang F, et al. (2009). Association between NSAIDs use and breast cancer risk: a systematic review and meta-analysis. Breast Cancer Res. Treat. 117: 141-150. 